RECEIVED

JAN 30 TYSib

$\theta$ STI

GA-A22107

CONF-0,506135--1

\title{
TARGET SUPPORT \\ FOR INERTIAL CONFINEMENT FUSION
}

\author{
by \\ K.R. SCHULTZ
}

AUGUST 1995 


\section{DISCLAIMER}

This report was prepared as an account of work sponsored by an agency of the United States Government. Neither the United States Government nor any agency thereof, nor any of their employees, makes any warranty, express or implied, or assumes any legal liability or responsibility for the accuracy, completeness, or usefulness of any information, apparatus, product, or process disclosed, or represents that its use would not infringe privately owned rights. Reference herein to any specific commercial product, process, or service by trade name, trademark, manufacturer, or otherwise, does not necessarily constitute or imply its endorsement, recommendation, or favoring by the United States Government or any agency thereof. The views and opinions of authors expressed herein do not necessarily state or refiect those of the United States Government or any agency thereof. 


\title{
TARGET SUPPORT \\ FOR INERTIAL CONFINEMENT FUSION
}

\author{
by \\ K.R. SCHULTZ
}

This is a preprint of a paper presented at the Fusion Industry Stakeholders Conference, June 15-16, 1995, in Washington, DC, and to be printed in the PROCEEDINGS.

\author{
Work supported by \\ the U.S. Department of Energy \\ under Contract No. DE-AC03-91SF18601
}

GA PROJECT 3896

AUGUST 1995

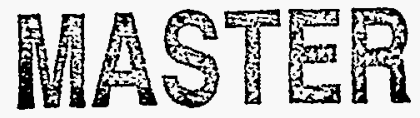




\title{
Target Support For Inertial Confinement Fusion
}

\author{
K. R. Schultz 1
}

General Atomics (GA) plays an important industrial support role for the U.S. Inertial Confinement Fusion program in the area of target technology. This includes three major activities: target fabrication support, target handling systems development, and target chamber design. The work includes target fabrication for existing ICF experiments, target and target system development for future experiments, and target research and target chamber design for experiments on future machines, such as the National Ignition Facility (NIF).

\section{TARGET FABRICATION SUPPORT}

General Atomics is under contract to the U.S. Department of Energy to provide target fabrication support services for the Inertial Confinement Fusion Program. GA provides target fabrication for the five ICF Labs: Los Alamos National Laboratory (LANL), Lawrence Livermore National Laboratory (LLNL), Sandia National Laboratory (SNL), Naval Research Laboratory (NRL), and University of Rochester Laboratory for Laser Energetics (UR/LLE), for their experiments on the NOVA, PBFA-II, NIKE, and OMEGA-Upgrade experiments. The work encompasses research into the target fabrication and characterization techniques for improved targets to ICF Lab specifications, development of these techniques into production processes, and target production and deliveries for the five ICF Labs. The target technologies provided include production of glass and plastic shells (or microballoons) which contain the fusion fuel, application of plastic and metal coatings on spherical shells, cylindrical hohlraum targets, and flat planar targets. ICF targets must be built to extremely tight specifications of accuracy in physical dimensions, materials content, and surface finish. To be able to assure that target deliveries meet the specifications, the physical dimensions, materials characteristics and surface finish must be characterized to still more precise standards. A significant amount of GA's effort is involved with development of more precise and more efficient target characterization techniques. GA also provides the micromachining of the hohlraums, and various witness plates and other target components needed for

1 K. R. Schultz, General Atomics, P.O. Box 85608, San Diego, California, 91286-9784, USA. indirect drive targets. GA has capability for deuterium and tritium fill of ICF target capsules.

Targets for direct drive ICF experiments consist of a spherical capsule that contains DT gas in the center and has multiple layers to contain the gas and provide material for ablation to cause capsule implosion. (1) An example is shown on Fig. 1. Indirect drive ICF experiments utilize very similar capsules encased in a metal container called a hohlraum. Pulsed energy from the laser or particle beam is deposited in the hohlraum, creating a sea of $\mathrm{x}$-rays, which in turn illuminate the capsule, causing ablation and compression. An example is shown on Fig. 2.

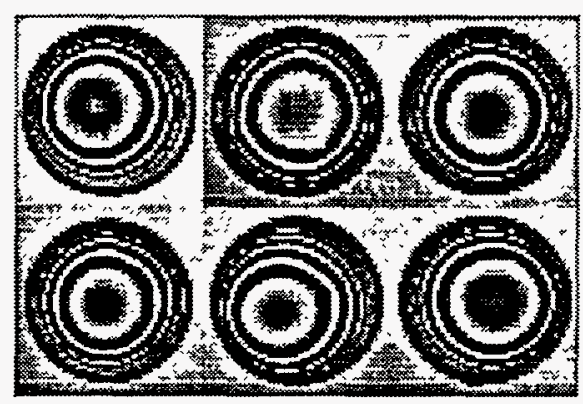

Fig. 1. Composite polymer capsules for LLNL, LANL, and URLLE.

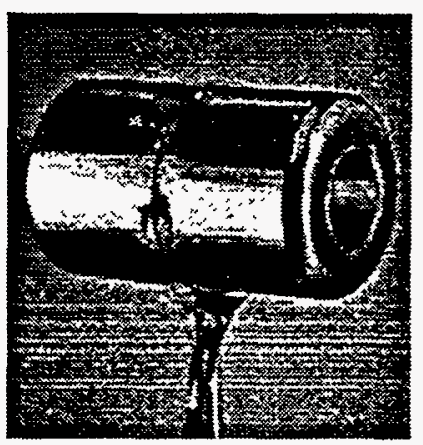

Fig. 2. Assembled indirect drive target for LLNL and LANL. 
GA's role as the Target Fabrication Support contractor is a team effort. GA's activities in San Diego are complimented by a major subcontractor and partner, W.J. Schafer Associates (WJSA), in their Livermore, California facility. We also have a small business subcontractor, Soane Technologies Incorporated, a polymer specialty house, located in Hayward, California.

\section{TARGET HANDLING SYSTEM SUPPORT}

To achieve ignition with a minimum investment in implosion energy, ignition targets will require cryogenic solid or liquid DT fuel layers to achieve high density with moderate compression. Target capsules will be filled by permeation; high pressure DT gas is allowed to permeate through the capsule wall to the interior. Since the capsules can only stand -5 atm over pressure without collapsing, and since the pressure required to achieve the DT layer thickness needed for cryogenic targets is $\sim 1100 \mathrm{~atm}$, very precise pressure control of the target environment during the fill process is required. When the capsule has reached full pressure, it must be cooled to cryogenic temperatures to condense the fuel so the pressure can be released. A capsule can only contain several tens of atmospheres internal pressure without bursting. Once cooled to cryogenic conditions, the target must be handled with strict temperature control $( \pm 2 \mathrm{~K})$. The cryogenic DT fuel must then be layered. It must be configured into a uniform spherical shell, $\sim 100 \mu \mathrm{m}$ thick inside the 1 to $2 \mathrm{~mm}$ diameter capsule.
The layering techniques to achieve this are being developed by the ICF Laboratories (LLNL, LANL, and UR/LLE), with GA/WJSA support. After layering and precise characterization of the frozen DT layer, the target must be inserted into the target chamber and positioned to $\sim \pm 5 \mu \mathrm{m}$ at target center in preparation for a target shot. During this time, the target temperature must be maintained to within $\pm 0.2 \mathrm{~K}$, with even stricter requirements on the temperature gradient across the target. This very precise thermal protection must be provided up until a few tens of milliseconds prior to the shot when the thermally protective shrouds can be withdrawn, exposing the target to the room temperature environment of the target chamber just prior to the laser shot.

General Atomics is designing, developing, and constructing the complete target handling system for the University of Rochester OMEGA-Upgrade laser experiment. (2) This system will fill targets to up to 1100 atms of DT, cool them to cryogenic temperatures, transport them from the target fill system into the experimental area building, layering them, characterize them, insert them into the OMEGA-Upgrade target chamber, and protect them until shot time. An additional requirement of the OMEGA-Upgrade system is very strict tritium inventory control. The University of Rochester has a one gram tritium inventory site license, which requires that all dead volumes in the tritium pressurization and target permeation system must be very strictly controlled to meet this limit. A schematic of the OMEGA-Upgrade handling system is shown on Fig. 3.

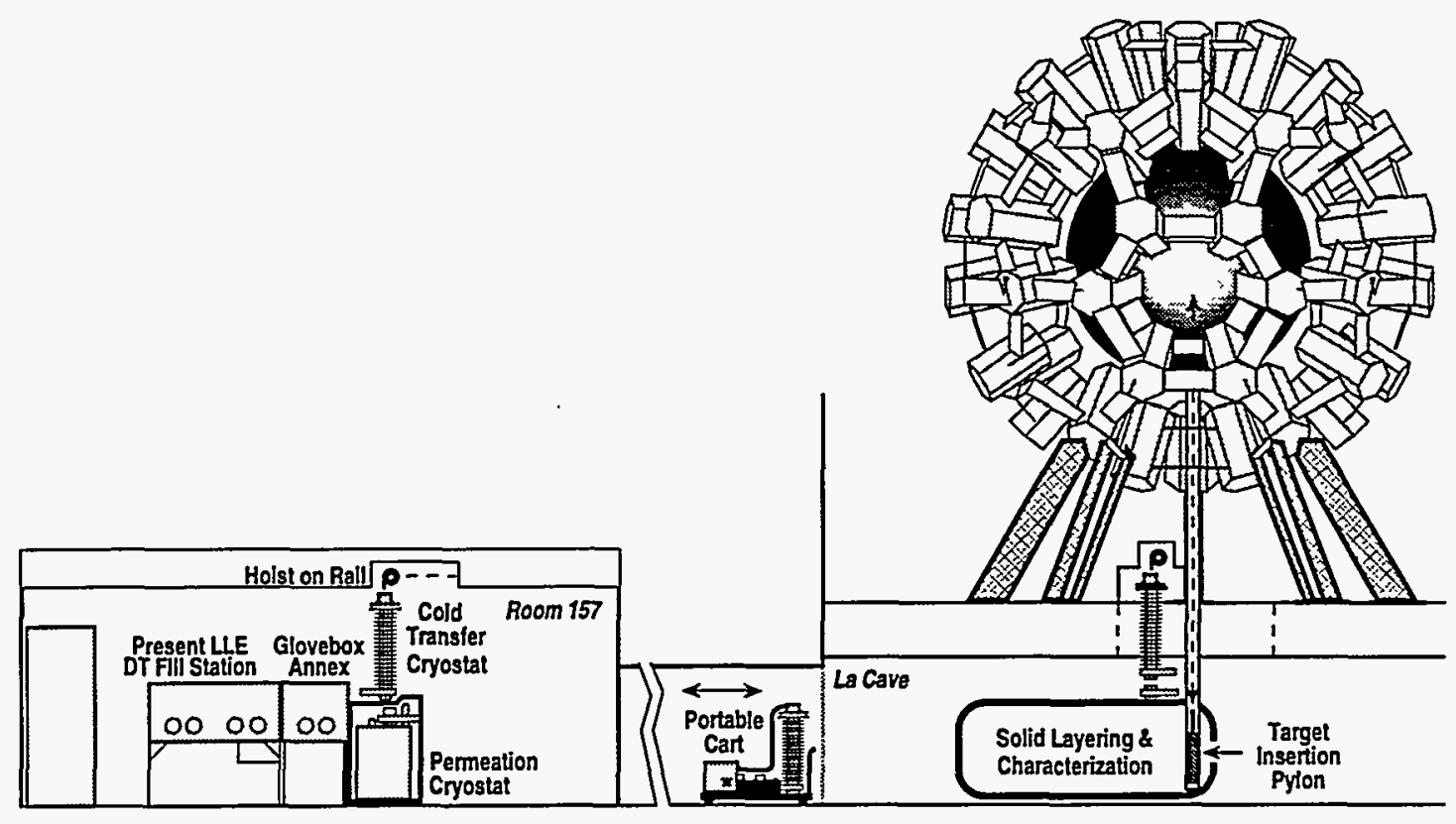

Fig. 3. Schematic of Omega Upgrade cryogenic target delivery system. 


\section{TARGET CHAMBER DESIGN SUPPORT}

General-Atomics has significant experience in fusion experiment vacuum chamber design and construction from our Magnetic Fusion program. This experience includes design, fabrication and operation of large vacuum chambers for Doublet III and DIII-D tokamak experiments, including the wall protection system of tiles and energy beam dumps. ${ }^{(3)}$ GA has applied this experience to designing ICF target chambers, for several potential future ICF experiments. These include the Laboratory Microfusion Facility (LMF) conceptual design activity in 1990, where GA's low activation aluminum target chamber design was chosen by LLNL for their LMF concept. $\left.{ }^{4}, 5\right)$ This design utilized high purity aluminum alloy structure to minimize long-term activation, a neutron shield consisting of borated water in aluminum tanks surrounding this chamber, and a water-frost first wall protection scheme, whereby a helium gas coolant in the first wall panels condensed water vapor into frost crystals on the interior of the wall. These frost crystals absorb the $\mathrm{x}$-ray and debris blast and protect the target chamber from erosion and thus protect the final optics from deposition of aluminum and other condensable materials. A schematic of this design is shown on Fig. 4.

GA has just begun work for LLNL, investigating use of very low activation organic matrix composite materials for the National Ignition Facility target chamber and in-chamber components. The intent of this exercise is to evaluate the feasibility of using very low activation materials to reduce the short-term dose rate in and around the target chamber immediately after a target shot. The present NIF design exhibits very low longterm activation, but ${ }^{27} \mathrm{Al}(\mathrm{n}, \alpha)^{24} \mathrm{Na}$ reactions will cause short half-life (15 hour) activation that will limit access to the chamber after a high yield shot. If the very low activation organic matrix composite materials are indeed practical for this application, they could further reduce the activation and allow contact maintenance in and around the chamber virtually immediately after a high yield shot.

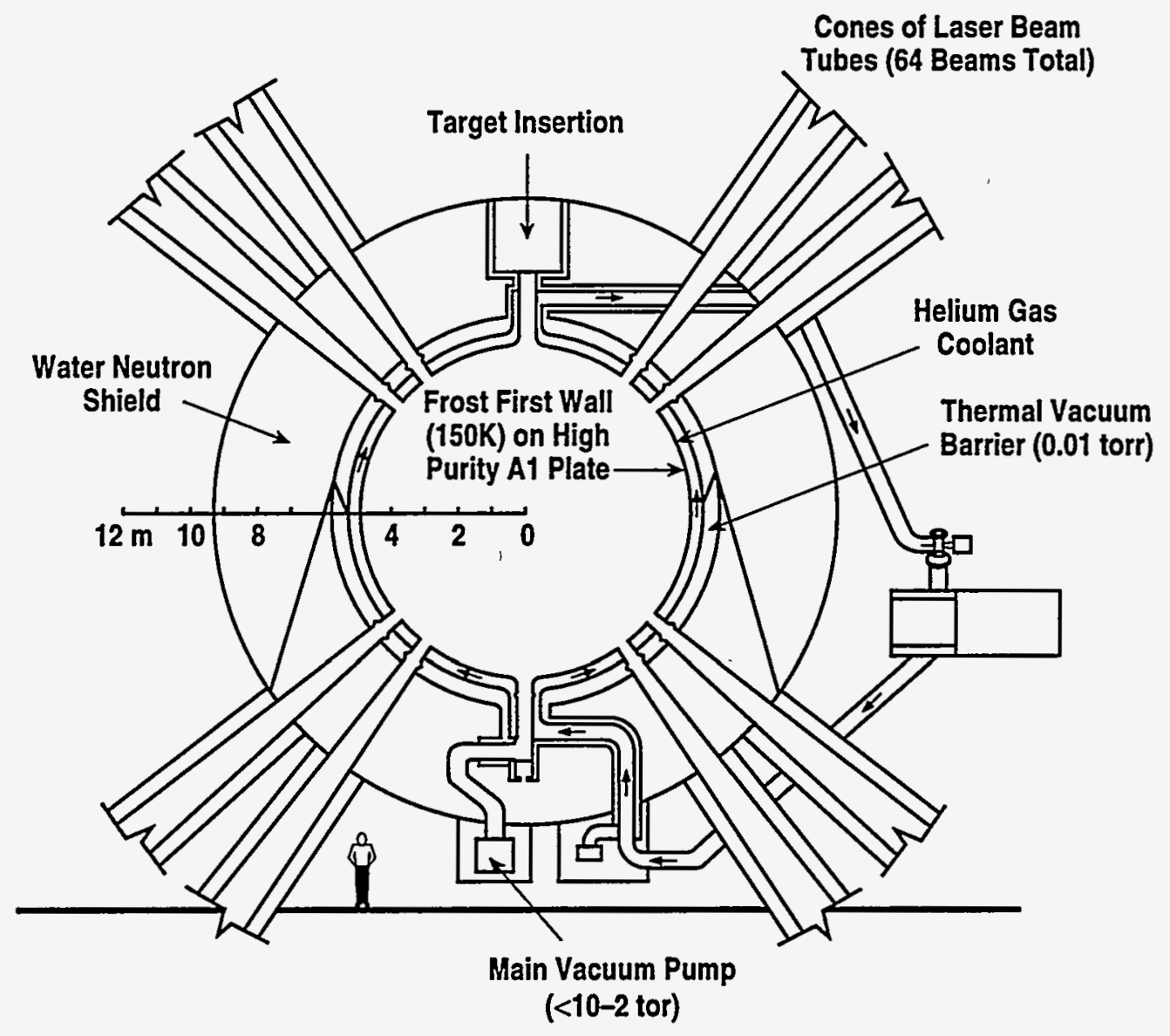

Fig. 4. Schematic diagram of containment chamber. 


\section{DISCUSSION}

GA's role in the Inertial Confinement Fusion Target Support area is a natural industrial role. Our responsibility is technology development, not target physics or even target design. Each of our tasks has a hardware deliverable item: target fabrication, target handling systems, and target chambers. In addition, our activities have not only present application, but future application. GA supports today's experiments and our work leads towards support of the National Ignition Facility, the Laboratory Microfusion Facility and Engineering Test Facility, a Demonstration Power Plant, and eventually commercial Power Plants. The eventual commercial end product of inertial fusion energy power plants gives special impetus to GA as an industry to participate. Our role is clearly a support role to the five ICF Laboratories, with a goal of applying and eventually commercializing the science being pursued at the National Labs.
This work is supported by the U.S. Department of Energy under Contract No. DE-AC03-91SF18601.

\section{REFERENCES}

1. K. R. Schultz and T. Norimatsu, "Inertial Fusion Target Development for Ignition and Energy," Proc. IAEA Tech. Com. Meeting on Drivers for Inertial Fusion, Paris, France, November 14-18, 1994.

2. R. Fagaly, et al., May 1995 Tritium Topical, "High Pressure Tritium Fill System for OMEGA-Upgrade ICF Laser," to be published in J. Fusion Energy.

3. R. Gallix, C. B. Baxi, et al., Proc. of 1985 IEEE Conference, "Design and Analysis of the DIII-D Vacuum Vessel," p. 842.

4. R.F: Bourque, et al., "Innovative Design Concepts for the LMF Target Chamber and Related Systems," General Atomics Report GA-A19651, June 1989.

5. "Laboratory Microfusion Capability Study Phase II Report," DOE/DP-0017, May 1993. 
